\title{
Neuropathic pain in primary knee osteoarthritis patients: correlation with physical function, quality of life, disease severity, and serum beta nerve growth factor levels
}

\author{
Shereen R. Kamel ${ }^{1,2^{*}}\left(\mathbb{D}\right.$, Radwa S. Ibrahim', Hend M. Moens ${ }^{3}$ and Rania M. Mohammed ${ }^{1}$
}

\begin{abstract}
Background: Neuropathic mechanisms are thought to play a role in knee osteoarthritis (KOA) pain. Neuropathic pain questionnaires can promote diagnosis of a neuropathic component. Thus, we aimed to assess the frequency of neuropathic pain in primary KOA patients (using clinical questionnaires) and to investigate its correlation with socio-demographic factors, physical function, quality of life, disease severity, and serum beta nerve growth factor ( $\beta$ NGF) levels.

Results: Seventy primary KOA patients were included. Neuropathic pain was detected in $52.9 \%$ of patients based on Douleur Neuropathique en 4 Questions (DN4) questionnaire and in 38.6\% of patients based on Leeds assessment neuropathic pain symptoms and signs questionnaire (LANSS). Serum $\beta$-NGF levels were significantly higher in KOA patients than controls $(P<0.0001)$, and in KOA patients with neuropathic pain compared with patients with non-neuropathic pain. DN4 score was positively correlated with Western Ontario and McMaster Universities Osteoarthritis Index (WOMAC) pain, stiffness, and physical function, and it was also negatively correlated with Osteoarthritis knee hip quality of life questionnaire (OAKHQOL) pain scores $\left(r_{s}=0.459, P<0.001 ; r_{s}=0.258, P=\right.$ $0.031 ; r_{s}=0.307, P=0.010 ; r_{s}=-0.337, P=0.004$, respectively), while LANSS scale was positively correlated with symptom duration, WOMAC stiffness, Lequesne pain, and Lequesne index $\left(r_{s}=0.260, P=0.020 ; r_{s}=0.343, P=0.004\right.$; $\left.r_{s}=0.344, P=0.004 ; r_{s}=0.322, P=0.007\right)$ and negatively correlated with OAKHQOL physical, OAKHQOL mental health, OAKHQOL social support, and total OAKHQOL scores $\left(r_{s}=-0.258, P=0.031 ; r_{s}=-0.254, P=0.034 ; r_{s}=-0.283, P=0.018\right.$; $r_{s}=-0.261, P=0.029$ respectively).
\end{abstract}

Conclusions: Neuropathic pain symptoms are frequent in primary KOA patients. KOA patients with neuropathic pain have worse quality of life, extreme disability, and higher serum $\beta$-NGF levels. Nerve growth factor inhibitors could have a potential role for not only relieving pain in KOA patients but also improving functional disability and quality of life in these patients.

Keywords: Neuropathic pain, Knee osteoarthritis, (DN4) questionnaire, (LANSS) questionnaire, Serum $\beta$-NGF

\footnotetext{
* Correspondence: shereen.refaat@mu.edu.eg

'Rheumatology and Rehabilitation Department, Faculty of Medicine, Minia University, Minia, Egypt

${ }^{2}$ Minia University Hospital, Minia, Egypt

Full list of author information is available at the end of the article
}

\section{Springer Open}

๑) The Author(s). 2021 Open Access This article is licensed under a Creative Commons Attribution 4.0 International License, which permits use, sharing, adaptation, distribution and reproduction in any medium or format, as long as you give appropriate credit to the original author(s) and the source, provide a link to the Creative Commons licence, and indicate if changes were made. The images or other third party material in this article are included in the article's Creative Commons licence, unless indicated otherwise in a credit line to the material. If material is not included in the article's Creative Commons licence and your intended use is not permitted by statutory regulation or exceeds the permitted use, you will need to obtain permission directly from the copyright holder. To view a copy of this licence, visit http://creativecommons.org/licenses/by/4.0/. 


\section{Background}

Osteoarthritis (OA) is a multifactorial disease, involving multiple causative factors as aging, trauma, biomechanical loading, inflammation, and metabolic disturbances $[1,2]$. It is classified into two groups according to its etiology: primary (idiopathic or nontraumatic) and secondary (usually due to trauma or mechanical misalignment or other articular disease). The disease is more common in middle-aged and older people over the age of 50 . The prevalence of knee osteoarthritis (KOA) among female patients is higher than that of male patients, and the prevalence rate of individuals aged over 65 years is 68\% [3].

Pain and local tenderness or pressure hyperalgesia around the affected joint are frequently manifested in OA [4]. OA pain mechanisms are complex; both peripheral and central processes are involved in creating the OA pain [5].

People with KOA may present with different pain phenotypes, nociceptive, inflammatory, and neuropathic pains $[5,6]$. Neuropathic component of OA pain, possibly emerging from peripheral and central pain sensitization mechanisms [7]. Recognizing specific aspects of joint pathology that contribute to different OA pain phenotypes might help identify pain phenotype specific peripheral treatment targets [8].

Several screening tools were used to differentiate neuropathic pain from non-neuropathic pain [9]. All screening tools have self-assessment questions. However, sensory examination is present in Leeds assessment of neuropathic pain symptoms and signs (LANSS) and Douleur Neuropathique 4 questions (DN4) questionnaires, which give them an objective significance and crucial findings for the diagnosis of neuropathic pain, among all the others [10].

Nerve growth factor (NGF) is a key mediator of acute and chronic pain. Different biological actions of NGF contribute to its pro-analgesic effects, including NGFinduced sensitization of peripheral nociceptive terminals and NGF-induced sprouting of sensory nerves [11]. Nerve growth factor binds tropomyosin receptor kinase A (TrkA) that is expressed in many sensory and sympathetic fibers and regulates survival of these neurons [12]. Elevated NGF levels are seen in individuals with chronic pain conditions [13], and intradermal or intramuscular injection of NGF causes allodynia and hyperalgesia in healthy subjects $[14,15]$.

The purpose of this study was to determine the frequency of neuropathic pain in patients with primary KOA (using the DN4 and LANSS questionnaires) and to investigate its correlation with socio-demographic factors, physical function, quality of life, and disease severity. Despite the fact that serum-NGF levels are increased in $\mathrm{KOA}$ patients, their probable links to neuropathic pain have never been investigated. Therefore, we aimed to assess serum $\beta$-NGF levels in KOA patients with neuropathic pain versus patients with non-neuropathic pain.

\section{Methods \\ Study design and population}

This study used an analytical cross-sectional design. Seventy patients (43 females and 27 males) with primary KOA who met ACR clinical and radiographic diagnostic criteria for primary KOA [16] were consecutively included. All patients were attending the Rheumatology and Rehabilitation outpatient clinic, Minia University Hospital, Minia governorate, Egypt-in the period from December 2018 to March 2019. All patients had knee pain for more than 3 months. The control population consisted of 21 (13 females/8 males) age-, sex-, and body mass index (BMI)-matched healthy volunteers (who are healthcare workers at the Main Hospital/for assessment of serum $\beta$-NGF levels) without any sign or disease suggestive of $\mathrm{OA}$, gout, rheumatoid arthritis, trauma, diabetes, and other orthopedic disorders like tendinitis, bursitis, and knee ligament injuries. Written informed consent was taken from all participants in the study. The study was approved by the ethics committee of the Faculty of Medicine. We had to enlist the help of research assistants who met with each illiterate patient and read out the questions in a way that they could understand, without necessarily affecting their responses.

Excluded from the study are patients with any previous history of knee surgery, history of steroid injections over the past 3 months, trauma, infection, known inflammatory arthritis such as rheumatoid arthritis, gout and other pain/neurological conditions such as radiculopathies, diabetes mellitus, stroke, and traumatic brain injury and patients who were already receiving medical treatment for neuropathic pain.

\section{Clinical assessment Anthropometrics}

Height was measured to the nearest $0.1 \mathrm{~cm}$, weight was measured in the upright position to the nearest $0.1 \mathrm{~kg}$, and BMI is calculated as weight in kilograms divided by the square of height in meters.

\section{Visual analogue scale}

Visual analogue scale (VAS) is a horizontal line, $100 \mathrm{~mm}$ in length, anchored byword descriptors at each end. The patient marks on the line the point that they represented their perception of their current state. A higher score indicates greater pain intensity [17]. 


\section{Western Ontario and McMaster University (WOMAC) Osteoarthritis Index}

The WOMAC is a valid and reliable instrument used for the assessment of OA of the lower extremities [18]. It consists of 24 items divided into 3 subscales. The pain scale includes five items asking about pain at activity or rest. The stiffness scale includes two questions. The function dimension explores the degree of difficulty in daily activities. The scores are summed for items in each subscale, with possible ranges as follows: pain $=0-20$, stiffness $=0-8$, physical function $=0-68$, and total WOMAC score is created by summing the items for all three subscales (0-96).

\section{Lequesne index}

Lequesne index was used to evaluate severity for knee disease. It is eleven-question survey, five questions pertaining to pain or discomfort, two questions dealing with maximum distance walked, and four questions about activities of daily living. The total questionnaire is scored on a 0 to 24 scale. Lower scores indicate there is less functional impairment [19].

\section{Osteoarthritis knee hip quality of life questionnaire (OAKHQOL)}

The patient's health-related quality of life was assessed using the OAKHQOL questionnaire, including 43 items in five main domains: physical activities (16 items), mental health (13 items), pain (4 items), social support (4 items), social functioning (3 items), and three independent items; each item is scored on a scale from 0 to 10 , and the normalized scores were obtained by computing the sum of item scores for each domain and calculated to a scale from 0 (worst) to 100 (best) [20]. We had to enlist the help of research assistants who met with each illiterate patient and read out the questions in a way that they could understand, without necessarily affecting their responses.

\section{Evaluation of neuropathic pain}

Detailed history taking, neurological examination, and two standardized screening tools were performed on all KOA patients. Screening tools were used for the purpose of distinguishing neuropathic pain from nonneuropathic pain.

\section{Douleur Neuropathique 4 questions (DN4 questionnaire)}

It was developed and validated in French and translated into 15 languages. It consists of 10 items that are either answered as YES or NO. Seven of these items assess pain quality, while the other 3 items detect the presence or absence of sensory allodynia and touch needle hypoesthesia based on clinical examination. Each item answered as "yes" yields 1 point, and a total score at or above $4 / 10$ is evaluated as positive [21]. Arabic version of DN4 questionnaire was used [22].

\section{Leeds assessment of neuropathic pain symptoms and signs (LANSS scale)}

The LANSS scale is a valid tool used for discriminating between neuropathic and nociceptive pain. It contains 5 symptom items and 2 clinical examination items, score $\geq 12$ suggest likely neuropathic pain [23]. Arabic version of LANSS scale was used in the present study [24].

\section{Radiological evaluation}

Grading of knee OA severity was performed using the Kellgren-Lawrence (KL) grading scale. The radiological severity was categorized into four grades as follows: very mild (grade 1), mild (grade 2), moderate (grade 3 ), and severe (grade 4) [25].

\section{ELISA for serum $\beta$-NGF}

Five millimeters of venous blood was withdrawn, collected in serum separator tubes, and allowed to clot for 10-20 $\mathrm{min}$ at room temperature. Centrifuge at 2000$3000 \mathrm{RPM}$ for $20 \mathrm{~min}$ and stored at $-80{ }^{\circ} \mathrm{C}$ for later use. Serum $\beta$-NGF levels were measured for patients and healthy controls using an enzyme-linked immunosorbent assay (ELISA) kit (SHANGHAI CRYSTAL DAY BIOTECH CO., LTD, China). Construct a standard curve by plotting the average OD for each standard on the vertical $(Y)$ axis against the concentration on the horizontal (X) axis and draw a best fit curve through the points on the graph. These calculations can be best performed with computer-based curve-fitting software and the best fit line can be determined by regression analysis.

\section{Statistical analysis}

The statistical analysis was performed using SPSS 22.0. Descriptive statistics were done by number and percent as well as mean and SD. Statistical differences between groups were tested using chi-square $\left(\chi^{2}\right)$ test for qualitative variables and independent sample $t$-test for quantitative normally distributed variables. Correlations were calculated using Spearman's correlation coefficient. Linear regression analysis was used to predict the risk factors for neuropathic pain in primary KOA patients. The level of statistical significance was set at a $P \leq 0.05$.

\section{Results}

Sociodemographic data of the studied population are shown in Table 1 . Nineteen patients (27.1\%) had knee effusion, 12 (17.1\%) had limited range of motion, and 9 (12.9\%) had joint deformity. Treatment included nonsteroidal anti-inflammatory drugs (NSAIDs) in 58 (82.9\%) patients and chondroprotective agents (polysulfated glycosaminoglycans) in 30 (42.9\%) patients. Thirty- 
Table 1 Sociodemographic data of the studied population

\begin{tabular}{|c|c|c|}
\hline & $\begin{array}{l}\text { KOA patients } \\
(n=70)\end{array}$ & $\begin{array}{l}\text { Healthy control } \\
(n=21)\end{array}$ \\
\hline Sex, female/male & $47 / 23$ & $13 / 8$ \\
\hline Age (years) & $53.39 \pm 8.004(32-68)$ & $51.19 \pm 9.4(31-70)$ \\
\hline BMI $\left(\mathrm{kg} / \mathrm{m}^{2}\right)$ & $\begin{array}{l}25.71 \pm 4.286(18.75- \\
35.9)\end{array}$ & $\begin{array}{l}24.15 \pm 3.12(19.2- \\
30)\end{array}$ \\
\hline $\begin{array}{l}\text { Symptom duration } \\
\text { (month) }\end{array}$ & $14.91 \pm 2.78(4-180)$ & NA \\
\hline \multicolumn{3}{|l|}{ Educational level } \\
\hline Primary school & 35 (50\%) & NA \\
\hline Illiterate & 30 (42.9\%) & \\
\hline Secondary school & $4(5.7 \%)$ & \\
\hline University & $1(1.4 \%)$ & \\
\hline \multicolumn{3}{|l|}{ Residence } \\
\hline Rural & 65 (92.9\%) & NA \\
\hline Urban & $5(7.1 \%)$ & \\
\hline
\end{tabular}

Values are labeled as mean \pm SD (range) or $n$. KOA knee osteoarthritis, BMI body mass index, NA not applicable. No statistically significant differences between groups $(P>0.05)$

six patients (51.4\%) were having mild OA, i.e., KL Grade II, whereas the rest were moderate to severe OA [28 (40\%) were having Grade III and 6 (8.6\%) were having Grade IV].

Patients who had scores $\geq 4$ from the DN4 questionnaire and scores $\geq 12$ from the LANSS scale were accepted to have neuropathic pain. According to this, neuropathic pain was detected in 37 patients (52.9\%) based on the DN4 questionnaire and in 27 patients $(38.6 \%)$ based on the LANSS scale. DN4 scale ranged between 2 and 8 with a mean of $4.39 \pm$ 1.51 while LANSS score ranged between 9 and 19 with a mean of $12.2 \pm 3.03$.

The frequency of responses for individual items of DN4 questionnaire and LANSS questionnaire among OA patients is shown in Tables 2 and 3.

Comparison of WOMAC scores, Lequesne scores, Kellgren-Lawrence scale, and normalized OAHKOQL scores between patients with neuropathic pain and those with non-neuropathic pain is shown in Tables 4 and 5 .

The mean serum $\beta$ NGF levels were significantly higher in KOA patients than control: $590.7 \pm 244.83 \mathrm{pg} / \mathrm{ml}$ versus $27.52 \pm 6.87 \mathrm{pg} / \mathrm{ml}$ respectively, $P<0.0001$. Moreover, the mean serum $\beta$ NGF levels were significantly higher in patients with neuropathic pain than patients with non-neuropathic pain as shown in Table 5.

The correlations of neuropathic pain scores with all of the studied parameters are shown in Table 6.

Linear regression analysis was employed to analyze the risk factors for neuropathic pain in primary knee OA. According to DN4 score, higher WOMAC pain, higher WOMAC physical function, higher total WOMAC, and higher $\beta$ NGF were significant risk factors $(P<0.001, P<0.001, P=0.002, P=0.039$ respectively). While according to LANSS score, longer symptom duration, higher WOMAC stiffness, higher Lequesne pain, lower social support OAKHQOL, lower total OAKHQOL, and higher serum $\beta$ NGF level were significant risk factors for neuropathic pain $(P=$ $0.026, P<0.001, P=0.048, P=0.019, P=0.036, P<$ 0.001 respectively).

Table 2 Frequency of responses for individual items of DN4 questionnaire among OA patients

\begin{tabular}{|c|c|c|c|c|}
\hline & \multicolumn{2}{|l|}{ OA patients $(n=70)$} & \multirow[t]{2}{*}{$t$} & \multirow[t]{2}{*}{$P$} \\
\hline & Patients with neuropathic pain $(n=37)$ & Patients with non-neuropathic pain $(n=33)$ & & \\
\hline \multicolumn{5}{|c|}{ Does the pain have one or more of the following characteristics? } \\
\hline Burning & $23(32.86 \%)$ & $9(12.9 \%)$ & 8.556 & $0.003^{*}$ \\
\hline Painful cold & $25(35.7 \%)$ & $9(12.9 \%)$ & 11.338 & $<0.001^{*}$ \\
\hline Electric shocks & $34(48.7 \%)$ & $14(20 \%)$ & 19.806 & $<0.001^{*}$ \\
\hline \multicolumn{5}{|c|}{ Is pain associated with one or more of the following in the same area? } \\
\hline Tingling & $16(22.9 \%)$ & $8(11.4 \%)$ & 2.795 & 0.095 \\
\hline Pins and needles & $31(44.3 \%)$ & $11(15.7 \%)$ & 18.498 & $<0.001^{*}$ \\
\hline Numbness & $21(30 \%)$ & $4(5.7 \%)$ & 15.136 & $<0.001^{*}$ \\
\hline Itching & $16(22.9 \%)$ & $11(15.7 \%)$ & 0.723 & 0.395 \\
\hline \multicolumn{5}{|c|}{ Is the pain located in an area where physical examination may reveal? } \\
\hline Touch hypoesthesia & $21(30 \%)$ & $15(21.4 \%)$ & 0.892 & 0.345 \\
\hline Pricking hypoesthesia & $16(22.9 \%)$ & $11(15.7 \%)$ & 0.723 & 0.395 \\
\hline \multicolumn{5}{|c|}{ In the painful area, can the pain be caused or increased by: } \\
\hline Brushing & $5(7 \%)$ & 1 (1.4\%) & 2.446 & 0.118 \\
\hline
\end{tabular}

Values are labeled as $n$ (\%). DN4 Douleur Neuropathique 4, OA Osteoarthritis

*Significant $P$ value $\leq 0.05$ 
Table 3 The frequency of responses for individual items of LANSS questionnaire among OA patients

\begin{tabular}{|c|c|c|c|c|}
\hline & \multicolumn{2}{|l|}{ OA patients $(n=70)$} & \multirow[t]{2}{*}{$t$} & \multirow[t]{2}{*}{$P$} \\
\hline & $\begin{array}{l}\text { Patients with neuropathic } \\
\text { pain }(n=27)\end{array}$ & $\begin{array}{l}\text { Patients with non-neuropathic } \\
\text { pain }(n=43)\end{array}$ & & \\
\hline \multicolumn{5}{|l|}{ Knee pain quality } \\
\hline Pins and needles, tingling or pricking & $25(35.7 \%)$ & $20(28.6 \%)$ & 15.340 & $\begin{array}{l}< \\
0.001^{*}\end{array}$ \\
\hline Autonomic skin changes & $18(25.7 \%)$ & $28(40 \%)$ & 0.018 & 0.894 \\
\hline Sensitive to light touch & $18(25.7 \%)$ & $24(34.3 \%)$ & 0.814 & 0.367 \\
\hline Sudden pain/electric shocks & $12(17.1 \%)$ & $10(14.3 \%)$ & 3.455 & 0.063 \\
\hline Burning pain & $24(34.3 \%)$ & $21(30 \%)$ & 11.588 & $\begin{array}{l}< \\
0.001^{*}\end{array}$ \\
\hline \multicolumn{5}{|l|}{ Sensory testing } \\
\hline $\begin{array}{l}\text { Pins and needles, tingling or burning on rubbing on } \\
\text { painful area }\end{array}$ & $10(14.3 \%)$ & $6(8.6 \%)$ & 5.012 & $0.025^{*}$ \\
\hline $\begin{array}{l}\text { Numbness or tenderness felt when pressing on painful } \\
\text { area }\end{array}$ & $17(24.3 \%)$ & $20(28.6 \%)$ & 1.801 & 0.180 \\
\hline
\end{tabular}

Values are labeled as $n$ (\%). LANSS Leeds assessment neuropathic pain symptoms and signs, OA osteoarthritis

*Significant $P$ value $\leq 0.05$

\section{Discussion}

In the present study, neuropathic pain was detected in $52.9 \%$ of patients based on the DN4 questionnaire and in $38.6 \%$ of patients based on the LANSS scale. According to DN4 questionnaire, the most frequently described neuropathic pain characteristic in KOA patients with neuropathic pain was a sensation of electric shock (48.7\%) with a significant difference compared to KOA patients with non-neuropathic pain, and on physical examination up to $30 \%$ had touch hypoesthesia, while

Table 4 Comparison of WOMAC scores, lequesene scores and Kellegren Lawrance scale between patients with neuropathic pain and those with non-neuropathic pain

\begin{tabular}{|c|c|c|c|c|c|c|c|c|c|}
\hline \multirow{2}{*}{\multicolumn{2}{|c|}{ Parameter mean \pm SD (range) }} & \multicolumn{4}{|c|}{ DN4 } & \multicolumn{4}{|c|}{ LANSS } \\
\hline & & $\begin{array}{l}\text { DN4 } \geq 4 \\
(n=37)\end{array}$ & $\begin{array}{l}\text { DN4 } \leq 3 \\
(n=33)\end{array}$ & $x^{2}$ & P value & $\begin{array}{l}\begin{array}{l}\text { LANSS }>12 \\
(\mathrm{n}=27)\end{array} \\
\end{array}$ & $\begin{array}{l}\text { LANSS }<12 \\
(n=43)\end{array}$ & $t$ & P value \\
\hline VAS & & $\begin{array}{c}6.57 \pm 1.59 \\
(3-9)\end{array}$ & $\begin{array}{c}6 \pm 1.46 \\
(3-8) \\
\end{array}$ & 1.550 & 0.126 & $\begin{array}{c}6.56 \pm 1.55 \\
(3-9)\end{array}$ & $\begin{array}{c}6.14 \pm 1.54 \\
(3-9)\end{array}$ & 1.098 & 0.276 \\
\hline \multirow{4}{*}{$\sum_{0}^{\frac{1}{3}}$} & Pain score $(0$ to 20$)$ & $\begin{array}{l}9.86 \pm 2.1 \\
(5-12)\end{array}$ & $\begin{array}{l}6.79 \pm 3.59 \\
(3-15)\end{array}$ & 4.439 & $<0.0001^{*}$ & $\begin{array}{l}8.26 \pm 3.46 \\
(3-15)\end{array}$ & $\begin{array}{l}8.51 \pm 3.17 \\
(3-14)\end{array}$ & 0.313 & 0.755 \\
\hline & Stiffness score (0 to 8$)$ & $\begin{array}{l}3.57 \pm 1.2 \\
(1-6)\end{array}$ & $\begin{array}{l}4 \pm 1.2 \\
(2-6)\end{array}$ & 1.527 & 0.131 & $\begin{array}{c}4.07 \pm 1.07 \\
(2-6)\end{array}$ & $\begin{array}{c}3.58 \pm 1.24 \\
(1-6)\end{array}$ & 1.704 & 0.093 \\
\hline & $\begin{array}{l}\text { Physical functional score (0 to } \\
\text { 68) }\end{array}$ & $\begin{array}{l}44.24 \pm 5.43 \\
(35-56)\end{array}$ & $\begin{array}{l}39.39 \pm 10.36 \\
(21-60)\end{array}$ & 2.491 & $0.015^{*}$ & $\begin{array}{l}42.89 \pm 8.4 \\
(28-60)\end{array}$ & $\begin{array}{l}41.37 \pm 8.7 \\
(21-59)\end{array}$ & 0.730 & 0.468 \\
\hline & Overall score (0 to 96) & $\begin{array}{l}56.81 \pm 6.62 \\
\quad(42-70)\end{array}$ & $\begin{array}{l}52.52 \pm 11.36 \\
(31-75)\end{array}$ & 1.959 & 0.054 & $\begin{array}{l}56.67 \pm 8.21 \\
(39-74)\end{array}$ & $\begin{array}{c}53.6 \pm 9.9 \\
(31-75)\end{array}$ & 1.342 & 0.184 \\
\hline \multirow{4}{*}{ 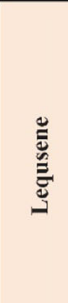 } & Pain score (0 to 8) & $\begin{array}{c}4.5 \pm 1.9 \\
(2-10)\end{array}$ & $\begin{array}{c}4.2 \pm 2.13 \\
(2-10)\end{array}$ & 0.629 & 0.532 & $\begin{array}{c}5 \pm 1.96 \\
(2-8)\end{array}$ & $\begin{array}{c}3.98 \pm 1.93 \\
(2-10)\end{array}$ & 2.144 & $0.036^{*}$ \\
\hline & $\begin{array}{l}\text { Maximum distance walked } \\
\text { score }(0 \text { to } 8)\end{array}$ & $\begin{array}{l}3.84 \pm 1.36 \\
(1-7)\end{array}$ & $\begin{array}{l}3.76 \pm 1.64 \\
(2-8)\end{array}$ & 0.223 & 0.824 & $\begin{array}{l}4.19 \pm 1.52 \\
\quad(2-8)\end{array}$ & $\begin{array}{c}3.56 \pm 1.44 \\
(1-7)\end{array}$ & 1.739 & 0.087 \\
\hline & $\begin{array}{l}\text { Activities of daily living score } \\
(0-8)\end{array}$ & $\begin{array}{l}3.53 \pm 1.14 \\
(1-5.5)\end{array}$ & $\begin{array}{c}3.44 \pm 1.3 \\
(1-5)\end{array}$ & 0.300 & 0.765 & $\begin{array}{l}3.7 \pm 1.1 \\
(2-6)\end{array}$ & $\begin{array}{c}3.35 \pm 1.3 \\
(1-6)\end{array}$ & 1.195 & 0.236 \\
\hline & Overall score (0 to 24) & $\begin{array}{l}11.9 \pm 3.5 \\
(6-21)\end{array}$ & $\begin{array}{l}11.45 \pm 3.83 \\
(6-19)\end{array}$ & 0.485 & 0.629 & $\begin{array}{l}12.9 \pm 3.46 \\
(6-19)\end{array}$ & $\begin{array}{c}10.9 \pm 3.55 \\
(6-21)\end{array}$ & 2.351 & $0.022 \%$ \\
\hline \multirow{3}{*}{ 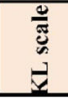 } & Grade II & $17(45.9 \%)$ & $19(57.6 \%)$ & \multirow{3}{*}{1.124} & \multirow{3}{*}{0.570} & $12(44.4 \%)$ & $24(55.8 \%)$ & \multirow{3}{*}{2.422} & \multirow{3}{*}{0.298} \\
\hline & Grade III & $16(43.2 \%)$ & $12(36.4 \%)$ & & & $11(40.7 \%)$ & $17(39.5 \%)$ & & \\
\hline & Grade IV & $4(10.8 \%)$ & $2(6.1 \%)$ & & & $4(14.8 \%)$ & $2(4.7 \%)$ & & \\
\hline
\end{tabular}

BMI body mass index, DN4 Douleur Neuropathique 4, LANSS Leeds assessment neuropathic pain symptoms and signs, VAS Visual analogue Scale, WOMAC Western Ontario and McMaster Universities Osteoarthritis Index, KL Kellegren Lawerence

*Significant $P$ value $\leq 0.05$ 
Table 5 Quality of life and serum $\beta$ NGF levels in patients with neuropathic pain versus those with non-neuropathic pain

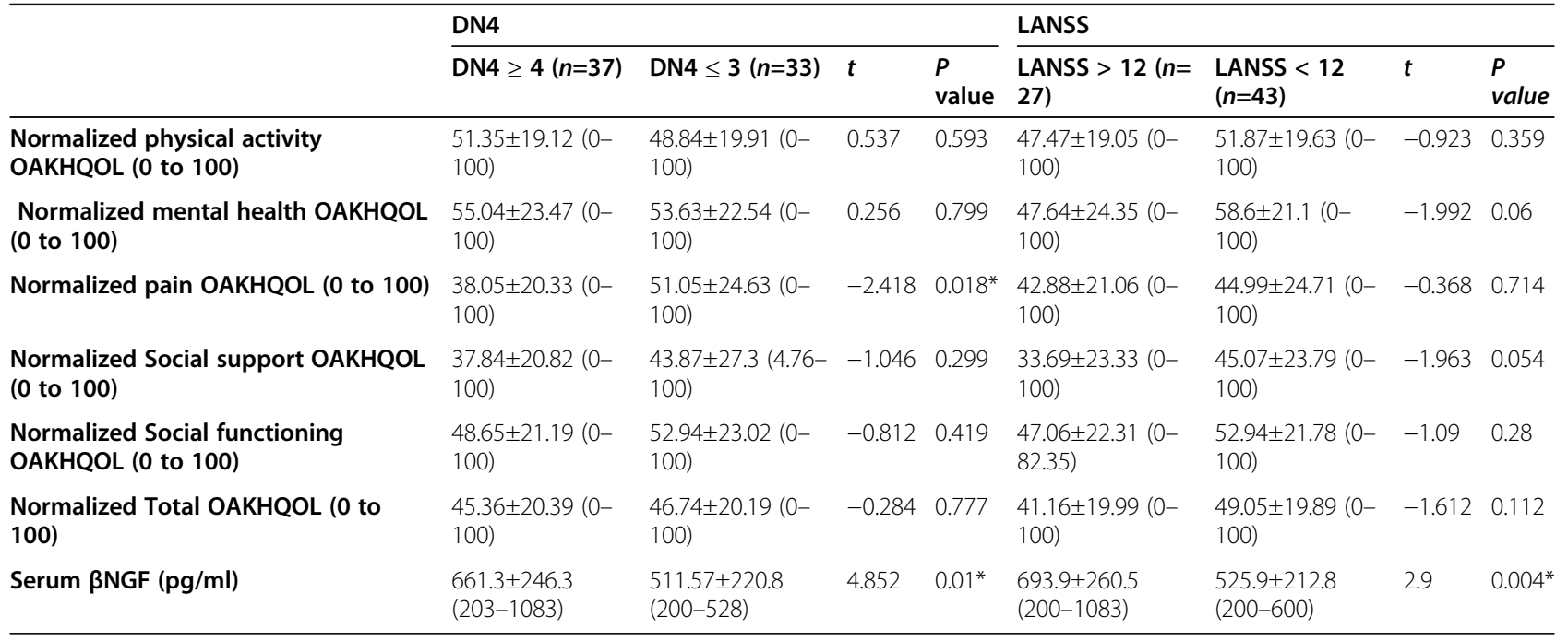

Values are labeled as mean \pm SD (range). OAKHQOL osteoarthritis knee hip quality of life, DN4 Douleur Neuropathique 4, LANSS Leeds assessment neuropathic symptoms and signs, $\beta N G F$ serum beta nerve growth factor

*Significant $P$ value $\leq 0.05$

Table 6 Correlations of total DN4 score and LANSS score with the studied parameters

\begin{tabular}{|c|c|c|c|c|}
\hline & \multicolumn{2}{|c|}{ DN4 score } & \multicolumn{2}{|c|}{ LANSS score } \\
\hline & $r_{s}$ & $P$ & $r_{s}$ & $P$ \\
\hline Symptom duration & 0.056 & 0.647 & 0.260 & $0.020^{*}$ \\
\hline Educational level & 0.061 & 0.616 & 0.065 & 0.590 \\
\hline VAS & 0.213 & 0.077 & 0.170 & 0.160 \\
\hline WOMAC pain & 0.459 & $<0.001^{*}$ & -0.015 & 0.902 \\
\hline WOMAC stiffness & 0.258 & $0.031^{*}$ & 0.343 & $0.004^{*}$ \\
\hline WOMAC physical function & 0.307 & $0.010^{*}$ & 0.145 & 0.231 \\
\hline Total WOMAC & 0.233 & 0.052 & 0.217 & 0.072 \\
\hline Lequesne pain & 0.128 & 0.291 & 0.344 & $0.004^{*}$ \\
\hline Lequesne maximum distance walked & 0.017 & 0.891 & 0.213 & 0.076 \\
\hline Lequesne daily activity & 0.062 & 0.608 & 0.143 & 0.239 \\
\hline Total Lequesne & 0.060 & 0.619 & 0.322 & $0.007^{*}$ \\
\hline OAKHQOL physical & 0.017 & 0.891 & -0.258 & $0.031^{*}$ \\
\hline OAKHQOL mental health & 0.029 & 0.81 & $0.254-$ & $0.034^{*}$ \\
\hline OAKHQOL pain & -0.337 & $0.004^{*}$ & -0.074 & 0.541 \\
\hline OAKHQOL social support & -0.107 & 0.376 & $0.283-$ & $0.018^{*}$ \\
\hline OAKHQOL social function & -0.12 & 0.323 & $0.145-$ & 0.232 \\
\hline Total OAKHQOL & -0.073 & 0.551 & $0.261-$ & $0.029^{*}$ \\
\hline KL scale & 0.107 & 0.379 & 0.099 & 0.414 \\
\hline$\beta N G F$ & 0.341 & $0.004^{*}$ & 0.313 & $0.008^{*}$ \\
\hline
\end{tabular}

Spearman's correlation test; *significant $P$ value $\leq 0.05$, VAS visual analogue scale, WOMAC Western Ontario and McMaster Universities Osteoarthritis Index, OAKHQOL osteoarthritis knee hip quality of life, DN4 Douleur Neuropathique 4, LANSS Leeds assessment neuropathic pain symptoms and signs, KL= KellgrenLawrence, $\beta N G F=$ beta nerve growth factor 
according to LANSS scale the most frequently knee pain quality symptom was pins and needles tingling or pricking (35.7\%) followed by burning pain (34.3\%) with a significant difference compared to KOA patients with nonneuropathic pain; however self-exam items revealed that $24.3 \%$ of patients had numbness or tenderness which felt when pressing on the painful area with a significant difference compared to patients with non-neuropathic pain and $14.3 \%$ had pins and needles, tingling or burning on rubbing on the painful area.

In agreement with our results, several studies reported the frequency of neuropathic pain in patients with KOA which was ranged from 17.6 to $51.9 \%$ (based on the DN4 questionnaire and/or LANSS scale) [26-34]. Other studies reported neuropathic pain in OA patients (based on the painDETECT questionnaire) in frequencies ranged from 20.7 to $66.7 \%$ [31, 35-37].

Asskın et al. [31] refereed the wide variation in the reported prevalence of neuropathic pain in OA to differences in methodology between studies and pain assessment tools.

Our results revealed that KOA patients with neuropathic pain as detected by DN4 questionnaire have significantly higher WOMAC pain, WOMAC physical function scores, and significantly lower normalized pain OAKHQOL score than patients with non-neuropathic pain $(P<0.0001, P=0.015, P=0.018$ respectively). Moreover, significantly higher Lequesne pain score and Lequesne index were found in KOA patients with neuropathic pain as detected by LANSS scale compared with patients without neuropathic pain $(P=0.036, P=0.022$ respectively).

In consistent with our results, Gölge et al. [27] found a highly significant difference between neuropathic and non-neuropathic groups as regards WOMAC pain score $(p<0.001)$, Aşkın et al. [31] also found a significant difference between both groups as regards WOMAC physical function $(p=0.04)$, Narayan et al. [32] found a significant difference between both groups as regards WOMAC total score $(p=0.024)$ and WOMAC physical function score $(p=0.008)$, Mahmoud et al. [38] study showed that the total score and normalized pain domain score were worst in the neuropathic group than the non-neuropathic group, and Radwan and Borai [33] found a highly significant difference between neuropathic and non-neuropathic pain groups as regards WOMAC physical function score, WOMAC pain score, and WOMAC total score ( $p<0.001$ for all of them).

We assessed serum $\beta$-NGF levels in the present study and we have found a significantly higher serum $\beta$-NGF levels in KOA patients than controls $(P<0.001)$, and significantly higher serum $\beta$-NGF levels in KOA patients with neuropathic pain "as detected by DN4 questionnaire and LANSS scale" compared with patients without neuropathic pain $(P=0.01, P=0.004$ respectively). In agreement with our results, a study of Montagnoli et al. [39] reported significantly higher serum and synovial $\beta$ NGF levels in KOA patients than controls. To our knowledge, no previous studies in the literature assessed serum $\beta$-NGF levels in KOA patients with neuropathic pain versus patients without neuropathic pain.

In the present study, the correlations of neuropathic pain scores with sociodemographic data, physical function, quality of life, and disease severity were investigated and we found that DN4 score was positively correlated with WOMAC pain, WOMAC stiffness, and WOMAC physical function and negatively correlated with $\mathrm{OAKH}-$ QOL pain scores $\left(r_{s}=0.459, P<0.001 ; r_{s}=0.258, P=0.031\right.$; $r_{s}=0.307, P=0.010 ; r s=-0.337, P=0.004$ respectively), while LANSS scale was positively correlated with symptom duration, WOMAC stiffness, Lequesne pain, and Lequesne index $(r s=0.260, P=0.020 ; r s=0.343, P=$ $\left.0.004 ; r_{s}=0.344, P=0.004 ; r s=0.322, P=0.007\right)$ and negatively correlated with OAKHQOL physical, OAKHQOL mental health, OAKHQOL social support, and total OAKHQOL scores $\left(r s=-0.258, P=0.031 ; r_{s}=\right.$ $-0.254, P=0.034 ; r_{s}=-0.283, P=0.018 ; r_{s}=-0.261, P=$ 0.029 respectively). In this way, we consider that KOA patients with neuropathic pain may have longer symptom duration, severe pain, extreme disability, and worse quality of life than patients with non-neuropathic pain.

A number of evidences indicate that $\beta$-NGF plays a significant role in osteoarthritis, not only in pain and hyperalgesia by nociceptor sensitization, but also as a key element of the inflammatory process $[40,41]$. Neuropathic pain is unresponsive to common analgesics, such as NSAIDs. Systemic central acting drugs as duloxetine, an antidepressant, have proven effective in controlling this type of pain in OA [42]. Agents blocking NGF might have therapeutic utility for pain [43].

Female sex, age, and BMI are well-known risk factors for OA, as shown in previous studies [44-46]. Also, a low level of education was found to be a significant factor associated with OA [47]. In the present study, we have found no correlation between neuropathic pain scores and risk factors. Study of Polat et al. [37] was consistent with our findings. In contrary to our results, Hochman et al. [35] found that the patients with neuropathic pain were younger and were more likely to be females, but there was no significant difference in level of education between patients with neuropathic pain and those without neuropathic pain.

Our results revealed no correlation between neuropathic pain scores and the Kellgren-Lawrence grades and this was consistent with the previous results of Narayan et al. [32], Polat et al. [37], and Radwan and Borai [33]. In contrary to our results, Ohtori et al. [36] reported that neuropathic pain tended to be seen in 
patients with KL grades of late stages OA; however, the majority of our patients had mild to moderate OA.

In the present study, according to linear regression analysis, longer symptom duration, higher pain scores, lower OAKHQOL score, and higher serum $\beta$ NGF levels were considered as significant risk factors for the development of neuropathic pain in KOA patients.

Our study has some limitations. Firstly, this study was cross-sectional with a relatively small number of patients. Secondly, we have not assessed for central sensitization by measuring pain pressure thresholds. Lastly, we did not assess $\beta$-NGF levels in synovial fluid and/or synovial tissue.

\section{Conclusions}

Neuropathic pain is frequent in KOA patients. Our study is the first one that assessed serum $\beta$-NGF levels in Egyptian primary KOA patients, and studied its correlation with the presence of neuropathic pain in OA. We recommend further studies which include larger number of KOA patients, in order to classify patients according to $\beta$-NGF levels, and further investigations to assess the role of $\beta$-NGF antagonists in relieving pain and improving functional status and quality of life in KOA patients.

\begin{abstract}
Abbreviations
KOA: Knee osteoarthritis; $\beta-N G F$ : Beta nerve growth factor; TrkA: Tropomyosin receptor kinase A; BMI: Body mass index; VAS: Visual analogue scale; WOMAC: Western Ontario and McMaster University; OAKHQOL: Osteoarthritis knee hip quality of life questionnaire; DN4: Douleur Neuropathique 4 questionnaire; LANSS: Leeds assessment of neuropathic pain symptoms and signs scale; KL: Kellgren-Lawrence grading scale; NSAIDs: Non-steroidal antiinflammatory drugs
\end{abstract}

\section{Acknowledgements}

We thank Professor Ebtesam Hassan, Public Health and Preventive Medicine department, Faculty of Medicine, Minia University, for her assistance with the statistics used in this research.

\section{Authors' contributions}

SK wrote the manuscript with input from all authors and supervised the work. RI examined the patients, collected the data, and performed the analysis. HM performed laboratory investigations. RM discussed the results and contributed to the final manuscript. All authors read and approved the final manuscript.

\section{Funding}

The authors received no financial support for the research.

\section{Availability of data and materials}

The datasets supporting the conclusions of this article are included within the article. The raw data can be requested from the corresponding author.

\section{Declarations}

\section{Ethics approval and consent to participate}

Written consent was taken from all participants in the study which was approved by the research ethics committee of the Faculty of Medicine, Minia University, Egypt. The study is a thesis and the committee's reference number is $112-11 / 2018$.
Consent for publication

Not applicable.

\section{Competing interests}

The authors declared no conflicts of interest.

\section{Author details}

${ }^{1}$ Rheumatology and Rehabilitation Department, Faculty of Medicine, Minia University, Minia, Egypt. ${ }^{2}$ Minia University Hospital, Minia, Egypt. ${ }^{3}$ Clinical

Pathology Department, Faculty of Medicine, Minia University, Minia, Egypt.

Received: 21 June 2021 Accepted: 6 September 2021

Published online: 09 November 2021

\section{References}

1. Ayhan E, Kesmezacar H, Akgun I (2014) Intraarticular injections (corticosteroid, hyaluronic acid, platelet rich plasma) for the knee osteoarthritis. World J Orthop 5(3):351-361. https://doi.org/10.5312/wjo.v5. i3.351

2. Guilak F (2011) Biomechanical factors in osteoarthritis. Best Pract Res Clin Rheumatol 25(6):815-823. https://doi.org/10.1016/j.berh.2011.11.013

3. Xu H, Zhao G, Xia F, Liu X, Gong L, Wen X (2019) The diagnosis and treatment of knee osteoarthritis: a literature review. Int J Clin Exp Med 12(5): 4589-4599 www.ijcem.com/ISSN:1940-5901/IJCEM0081354

4. Lee Y, Lu B, Bathon J, Haythornthwaite J, Smith M, Page G, Edwards RR (2011) Pain sensitivity and pain reactivity in osteoarthritis. Arthritis Care Res 63(3):320-327. https://doi.org/10.1002/acr.20373

5. Fu K, Robbins S, McDougall J (2017) Osteoarthritis: the genesis of pain. J Rheumatol 57(suppl_4):iv43-iv50

6. Moss P, Benson H, Will R, Wright A (2018) Patients with knee osteoarthritis who score highly on the PainDETECT questionnaire present with multimodality hyperalgesia, increased pain, and impaired physical function. Clin J Pain 34(1):15-21. https://doi.org/10.1097/AJP.0000000000000504

7. Dimitroulas T, Duarte R, Behura A, Kitas G, Raphael J (2014) Neuropathic pain in osteoarthritis: a review of pathophysiological mechanisms and implications for treatment. Semin Arthritis Rheum 44(2):145-154. https://doi. org/10.1016/j.semarthrit.2014.05.011

8. Nwosu L, Mapp P, Chapman V, Walsh D (2016) Relationship between structural pathology and pain behaviour in a model of osteoarthritis (OA). Osteoarthr Cartil 24(11):1910-1917. https://doi.org/10.1016/j.joca.2016.06.012

9. Cruccu G, Truini A (2009) Tools for assessing neuropathic pain. PLoS Med 6(4):e1000045. https://doi.org/10.1371/journal.pmed.1000045

10. Unal-Cevik I, Sarioglu-Ay S, Evcik D (2010) A comparison of the DN4 and LANSS questionnaires in the assessment of neuropathic pain: validity and reliability of the Turkish version of DN4. J Pain 11(11):1129-1135. https://doi. org/10.1016/j.jpain.2010.02.003

11. Denk F, Bennett DL, Mcmahon SB (2017) Nerve growth factor and pain mechanisms. Annu Rev Neurosci 40(1):307-325. https://doi.org/10.1146/a nnurev-neuro-072116-031121

12. Chang DS, Hsu E, Hottinger DG, Cohen SP (2016) Anti-nerve growth factor in pain management: current evidence. J Pain Res 9:373-383. https://doi. org/10.2147/JPR.S89061

13. Walsh DA, McWilliams DF, Turley MJ, Dixon MR, Fransès RE, Mapp PI et al (2010) Angiogenesis and nerve growth factor at the osteochondral junction in rheumatoid arthritis and osteoarthritis. Rheumatology (Oxford) 49(10): 1852-1861. https://doi.org/10.1093/rheumatology/keq188

14. Dyck PJ, Peroutka S, Rask C, Burton E, Baker MK, Lehman KA, Gillen DA, Hokanson JL, O'Brien PC (1997) Intradermal recombinant human nerve growth factor induces pressure allodynia and lowered heat-pain threshold in humans. Neurology 48(2):501-505. https://doi.org/10.1212/WNL.48.2.501

15. Svensson P, Cairns BE, Wang K, Arendt-Nielsen L (2003) Injection of nerve growth factor into human masseter muscle evokes long-lasting mechanical allodynia and hyperalgesia. Pain 104(1):241-247. https://doi.org/10.1016/S03 04-3959(03)00012-5

16. Altman $\mathrm{R}$, Asch $\mathrm{E}$, Bloch D, Bole G, Borenstein D, Brandt K, Christy W, Cooke TD, Greenwald R, Hochberg M, Howell D, Kaplan D, Koopman W, Longley S, Mankin H, McShane DJ, Medsger T, Meenan R, Mikkelsen W, Moskowitz R, Murphy W, Rothschild B, Segal M, Sokoloff L, Wolfe F (1986) Development of criteria for the classification and reporting of osteoarthritis: classification of osteoarthritis of the knee.Arthritis. Rheum 29(8):1039-1049. https://doi. org/10.1002/art.1780290816 
17. Bijur P, Silver GE (2001) Reliability of the visual analog scale for measurement of acute pain. Acad Emerg Med 8(12):1153-1157. https://doi. org/10.1111/j.1553-2712.2001.tb01132.x

18. Roos M, Lohmander LS (1999) WOMAC Osteoarthritis Index: reliability, validity, and responsiveness in patients with arthroscopically assessed osteoarthritis. Scand J Rheumatol 28(4):210-215. https://doi.org/10.1080/03 009749950155562

19. Lequesne M, Mery C, Samson M, Gerard P (1987) Indexes of severity for osteoarthritis of the hip and knee: validation-value in comparison with other assessment tests. Scand J Rheumatol 16(sup65):85-89

20. Rat A, Coste J, Pouchot J, Baumann M, Spitz E, Retel-Rude N et al (2005) OAKHQOL: a new instrument to measure quality of life in knee and hip osteoarthritis. J Clin Epidemiol 58(1):47-55. https://doi.org/10.1016/j.jclinepi.2 004.04.011

21. Bouhassira D, Attal N, Alchaar H, Boureau F, Brochet B, Bruxelle J, Cunin G, Fermanian J, Ginies P, Grun-Overdyking A, Jafari-Schluep H, Lantéri-Minet M, Laurent B, Mick G, Serrie A, Valade D, Vicaut E (2005) Comparison of pain syndromes associated with nervous or somatic lesions and development of a new neuropathic pain diagnostic questionnaire (DN4). Pain 114(1-2):2936. https://doi.org/10.1016/j.pain.2004.12.010

22. Terkawi A, Abolkhair A, Didier B, Alzhahrani T, Alsohaibani M, Terkawi Y, Almoqbali Y, Tolba YY, Pangililan E, Foula F, Tsang S (2017) Development and validation of Arabic version of the douleur neuropathique 4 questionnaire. Saudi J Anaesth 11(1):S31. https://doi.org/10.4103/sja.SJA_ 97 17

23. Bennett M (2001) The LANSS Pain Scale: the Leeds assessment of neuropathic symptoms and signs. Pain 92(1-2):147-157. https://doi.org/10.1 016/S0304-3959(00)00482-6

24. Garoushi S, Johnson M, Tashani O (2017) Translation and cultural adaptation of the Leeds Assessment of Neuropathic Symptoms and Signs (LANSS) pain scale into Arabic for use with patients with diabetes in Libya. Libyan J Med 12(1):1384288. https://doi.org/10.1080/19932820.2017.1384288

25. Kellgren J, Lawrence J (1957) Radiological assessment of osteo-arthrosis. Ann Rheum Dis 16(4):494-502. https://doi.org/10.1136/ard.16.4.494

26. Turovskaya E, Alekseeva L (2013) SAT0325 Neurological Mechanisms of Chronic Pain in Knee Osteoarthritis. Ann Rheum Dis 72(3):693-A6A693. https://doi.org/10.1136/annrheumdis-2013-eular.2050

27. Gölge U, Sen H, Kuyucu E, Sen H, GöKsel F, Kaymaz B et al (2015) Investigation of knee pain in osteoarthritic and neuropathic pain awareness. Acta Orthop Belg 81(4):639-646

28. Moreton B, Tew V, das Nair R, Wheeler M, Walsh D, Lincoln N (2015) Pain phenotype in patients with knee osteoarthritis: classification and measurement properties of painDETECT and self-report Leeds assessment of neuropathic symptoms and signs scale in a cross-sectional study. Arthritis Care Res 67(4):519-528. https://doi.org/10.1002/acr.22431

29. Oteo-Álvaro Á, Ruiz-Ibán MA, Miguens X, Stern A, Villoria J, Sánchez-Magro I (2015) High prevalence of neuropathic pain features in patients with knee osteoarthritis: a cross-sectional study. Pain Pract 15(7):618-626. https://doi. org/10.1111/papr.12220

30. Povoroznyuk V, Pryimych U (2016) AB0765 Identification of neuropathic pain component in patients of various age with knee osteoarthritis. Ann Rheum Dis 22(1):545-546. https://doi.org/10.1136/annrheumdis-2016-eular.1 705

31. Aşkın A, Özkan A, Tosun A, Demirdal Ü, İsnaç F (2017) Quality of life and functional capacity are adversely affected in osteoarthritis patients with neuropathic pain. Kaohsiung J Med Sci 33(3):152-158. https://doi.org/10.101 6/j.kjms.2016.12.007

32. Narayan RV, Thabah MM, Poduval M (2017) Neuropathic pain among patients with primary knee osteoarthritis: results of a cross-sectional study from a tertiary care center in Southern India. Indian J Rheumatol 12(3):132

33. Radwan A, Borai A (2018) Neuropathic pain in Egyptian patients with primary knee osteoarthritis: relationship with functional status and radiological severity. Egypt Rheumatol 41(4):261-264

34. Yildirim M, Öneș K, GÖkȘenoglu G (2019) Assessment of frequency of neuropathic pain in knee osteoarthritis and its relation to functional state, quality of life and depression. J Phys Med Rehabs 22(3):102-107. https://doi. org/10.31609/jpmrs.2019-70004

35. Hochman J, Gagliese L, Davis A, Hawker G (2011) Neuropathic pain symptoms in a community knee OA cohort. Osteoarthr Cartil 19(6):647-654. https://doi.org/10.1016/j.joca.2011.03.007
36. Ohtori S, Orita $S$, Yamashita M, Ishikawa T, Ito T, Shigemura T, Nishiyama $H$, Konno S, Ohta H, Takaso M, Inoue G, Eguchi Y, Ochiai N, Kishida S, Kuniyoshi K, Aoki Y, Arai G, Miyagi M, Kamoda H, Suzkuki M, Nakamura J, Furuya T, Kubota G, Sakuma Y, Oikawa Y, Suzuki M, Sasho T, Nakagawa K, Toyone T, Takahashi K (2012) Existence of a neuropathic pain component in patients with osteoarthritis of the knee. Yonsei Med J 53(4):801-805. https:// doi.org/10.3349/ymj.2012.53.4.801

37. Polat C, Doğan A, Özcan D, Köseoğlu B, Akselim S (2017) Is there a possible neuropathic pain component in knee osteoarthritis? Arch Rheumatol 32(4): 333-338. https://doi.org/10.5606/ArchRheumatol.2017.6006

38. Mahmoud GA, Moghazy A, Fathy S, Niazy MH (2019) Osteoarthritis knee hip quality of life questionnaire assessment in Egyptian primary knee osteoarthritis patients: Relation to clinical and radiographic parameters. Egypt Rheumatol 41(1):65-69. https://doi.org/10.1016/j.ejr.2018.05.001

39. Montagnoli C, Tiribuzi R, Crispoltoni L, Pistilli A, Stabile A, Manfreda F et al (2017) $\beta$-NGF and $\beta-N G F$ receptor upregulation in blood and synovial fluid in osteoarthritis. Biol Chem 398(9):1045-1054. https://doi.org/10.1515/hsz-2 016-0280

40. Wu Z, Nagata K, lijima T (2000) Immunohistochemical study of NGF and its receptors in the synovial membrane of the ankle joint of adjuvant-induced arthritic rats. Histochem Cell Biol 114(6):453-459. https://doi.org/10.1007/ s004180000222

41. Seidel M, Herguijuela M, Forkert R, Otten U (2010) Nerve growth factor in rheumatic diseases. Semin Arthritis Rheum 40(2):109-126. https://doi.org/1 0.1016/j.semarthrit.2009.03.002

42. Havelin J, Imbert I, Cormier J, Allen J, Porreca F, King T (2016) Central sensitization and neuropathic features of ongoing pain in a rat model of advanced osteoarthritis. J Pain 17(3):374-382. https://doi.org/10.1016/j.jpa in.2015.12.001

43. Hefti $F$ (2019) Pharmacology of nerve growth factor and discovery of tanezumab, an anti-nerve growth factor antibody and pain therapeutic. Pharmacol Res 154:104240

44. Hart D, Doyle D, Spector T (1999) Incidence and risk factors for radiographic knee osteoarthritis in middle-aged women: the Chingford Study. Arthritis Rheum 42(1):17-24. https://doi.org/10.1002/1529-0131(199901)42:1<17::A ID-ANR2>3.0.CO;2-E

45. Lohmander L, De Verdier M, Rollof, Nilsson P, Engström G (2009) Incidence of severe knee and hip osteoarthritis in relation to different measures of body mass: a population-based prospective cohort study. Ann Rheum Dis 68(4):490-496. https://doi.org/10.1136/ard.2008.089748

46. Nishimura A, Hasegawa M, Kato K, Yamada T, Uchida A, Sudo A (2011) Risk factors for the incidence and progression of radiographic osteoarthritis of the knee among Japanese. Int Orthop 35(6):839-843. https://doi.org/10.1 007/s00264-010-1073-x

47. Lee K, Chung C, Sung K, Lee S, Won S, Kim T et al (2015) Risk factors for osteoarthritis and contributing factors to current arthritic pain in South Korean older adults. Yonsei Med J 56(1):124-131. https://doi.org/10.3349/ ymj.2015.56.1.124

\section{Publisher's Note}

Springer Nature remains neutral with regard to jurisdictional claims in published maps and institutional affiliations.

\section{Submit your manuscript to a SpringerOpen ${ }^{\circ}$ journal and benefit from:}

- Convenient online submission

- Rigorous peer review

- Open access: articles freely available online

- High visibility within the field

- Retaining the copyright to your article

Submit your next manuscript at $>$ springeropen.com 